Sharif University of Technology
Scientia Iranica
SCIENTIA
I RAN I CA

Research Note

\title{
Application of neural network models to improve prediction accuracy of wave run-up on antifer covered breakwater
}

\author{
A. Rabiei*, A. Najafi-Jilani and M. Zakeri-Niri \\ Department of Civil Engineering, Islamic Azad University, Islamshahr Branch, Islamshahr, Iran. \\ Received 25 September 2013; received in revised form 18 September 2014; accepted 18 April 2016
}

\author{
KEYWORDS \\ Wave run-up; \\ Breakwater; \\ Artificial neural \\ network; \\ Multi-Layer \\ Perceptron (MLP); \\ MSE.
}

\begin{abstract}
The primary goal of this study is to present a better way in terms of cost and experimenting duration, instead of using experimental ways for investigating the wave run-up (Ru) over rubble-mound breakwater and examining the effect of placement pattern of antifer units on the amount of wave run-up. To do so, Artificial Neural Networks (ANNs) are suggested. For the sake of comparison, the proposed modeling is put into contrast by the ones obtained via other approaches in the literature. The Multi-Layer Perceptron (MLP) is selected as the artificial neural network is exerted in this study. In the designed neural network, the numbers of inputs and outputs are selected as four and one, respectively. On the other hand, the number of neurons in the single hidden layer of the network should be determined by trial and error considering the Mean Square Error (MSE) of the training and validation samples, which has been chosen as seven in this paper. The regression equations and MSE for the results obtained by ANN are presented in this paper and are compared with other models in the literature. Moreover, the regular placement is preferred to other placement patterns due to its less MSE obtained by ANN.
\end{abstract}

(C) 2017 Sharif University of Technology. All rights reserved.

\section{Introduction}

Wave run-up has always been important for coastal structures such as breakwaters. Many studies have been carried out on the effect of wave run-up on the rubble-mound breakwater covered by armor units with various placement patterns. there are some studies which can be mentioned such as that of Yagci and Kapdasli proposing alternative placement technique for antifer units [1], and Gunbak mainly focusing on the wave run-up on different types of armor

*. Corresponding author. Tel.: +98 21 7742-9532;

Fax: $+98212275-4233$

E-mail addresses: Arezoo.rabiei1@gmail.com (A. Rabiei); a. jilani@iiau.ac.ir (Najafi-Jilani); zakeri@iiau.ac.ir (M. Zakeri-Niri) blocks, such as rock, Accropod, Antifer, Cube, and Tetropad [2].

On the other hand, since the maximum wave run-up $(\mathrm{Ru})$ is an important parameter in the design of breakwater, Shankar showed effects of geometrical, structural, and hydraulic parameters on wave runup [3]. Also, Hudson et al. concluded that the wave run-up mostly depends on the types of armor units and their placement pattern [4]. Furthermore, wave run-up is one of the main physical processes in the design of the breakwater. Being able to estimate wave run-up accurately can lead to a more economical design.

The study of the run-up process has been the subject of many analytical, numerical, and experimental studies, such as Synolakis's studies, in which he concluded that the run-up variation is different for breaking and non-breaking solitary waves. The 
recent experiments of Synolakis are important in the confirmation of analytical and numerical results for the run-up process due to the precision of their experimental techniques in comparison with the earlier studies [5].

The new techniques of wave run-up investigation were reported by Bakhtyar et al. They used neural networks to present an appropriate prediction method for wave run-up on each armor unit based on its considerable roughness and permeability [6].

Between 1976 and 1978, the studies on the design of armor showed that blocks with simple cubic shape did not ensure sufficiently the stability of the armor layer; thus, the studies on the blocks grooved on four sides were carried out [7]. Among other research studies, the important ones are "wave run-up" Battjes (1971) [8], Synolakis (1986) [9,10], Van der Meer and Stam (1992) [11], Li \& Raichlen (2001) [12], Van de Walle (2003) [13], Hughes (2004) [14], Schuttrumpf et al. (2010) [15], Dentale et al. (2013) [16,17], Erdik (2014) [18], Najafi-Jilani et al. (2014) [19], Altomare et al. (2014) [20], and Crespo et al. (2014) [21], Kim et al. [22] and Rabiei et al. (2014) [23]. In addition, some of researchers have used SPH model to simulate wave run-up $[20,21]$.

In the present research, the experimental data are extracted from the paper proposed by Najafi-Jilani and Monshizadeh [5]. The objective of the investigation is to determine a placement pattern of antifer units and its effect on the amount of wave run-up.

\section{Materials and methods}

Najafi-Jilani and Monshizadeh (2010) [5] carried out experiments at a $2.5 \mathrm{~m}$ high, $1 \mathrm{~m}$ wide, and $25 \mathrm{~m}$ long wave flume, at hydro-environmental laboratory of the Water Research Institute in Iran.

At the end of the flume, there was the breakwater section. The regular wave was made by wave maker. Several variables were considered as the main variable parameters in the experiments. These variables were as follows: the placement patterns of antifer units, the front slope angle of the rubble-mound breakwater $(\cot \alpha)$, the incident wave height $\left(H_{i}\right)$, incident wave period $(T)$, and mean water depth $\left(h_{0}\right)$.

They [5] presented the result of laboratory tests and estimated the wave run-up on the slopes covered by antifer units in regular and irregular placement patterns:

$$
\frac{R}{h_{0}}=K_{p}\left(\frac{\pi}{2 \alpha}\right)^{0.18}\left(\frac{H_{i}}{h_{0}}\right)^{0.23}\left(\frac{H_{i}}{L_{i}}\right)^{-0.15}
$$

where $R$ is wave run-up, $h_{0}$ is still water depth, $H_{i}$ is incident wave height, $L_{i}$ is wave length, and $K_{p}$ is a coefficient based on the placement pattern of

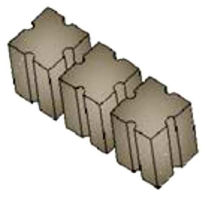

(a)

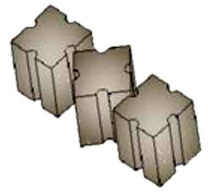

(b)

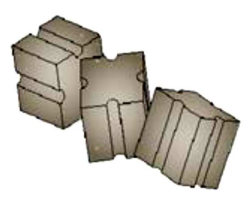

(c)
Figure 1. Various placement of the antifer units: (a) Regular; (b) irregular Type A; and (c) irregular Type B used in Jilani's experiments [5].

antifer units, which is equal to 1.25 for regular, 1.1 for irregular-type $\mathrm{A}$, and 0.85 for irregular-type B (Figure 1).

Hughes [14] performed several experiments on impermeable smooth bed, then he predicted non-breaking wave run-up as:

$$
\frac{R}{h_{0}}=3.84 \tan \alpha\left(\frac{M_{F}}{\gamma_{\omega} h_{0}^{2}}\right)^{\frac{1}{2}}
$$

where $\gamma_{\omega}$ is the water density, and $M_{F}$ is momentum flux of the incident wave. Dimensionless momentum flux was given as:

$$
\begin{aligned}
\left(\frac{M_{F}}{\gamma_{\omega} h^{2}{ }_{0}}\right)= & {\left[\left(\frac{H_{1}}{h_{0}}\right)^{2}+2\left(\frac{H_{1}}{h_{0}}\right)\right]+\frac{N^{2}}{2 M}\left(\frac{H_{1}}{h_{0}}+1\right) } \\
& \left\{\tan \left[\frac{M}{2}\left(\frac{H_{1}}{h_{0}}+1\right)\right]\right. \\
& \left.+\frac{1}{3} \tan ^{3}\left[\frac{M}{3}\left(\frac{H_{1}}{h_{0}}+1\right)\right]\right\}
\end{aligned}
$$

where $M$ and $N$ are empirical coefficients, and are introduced as:

$$
\begin{aligned}
& M=0.98\left\{\tanh \left[2.24\left(\frac{H_{1}}{h_{0}}\right)\right]\right\}^{0.44}, \\
& N=0.69 \tanh \left[2.38\left(\frac{H_{1}}{h_{0}}\right)\right] .
\end{aligned}
$$

Large differences of research studies have been conducted on wave run-up, and some of basic formulae have been expanded based on laboratory experiments. Synolakis [10] proposed a particular model for the analysis of maximum run-up for non-breaking wave on smooth and impermeable plane slopes in which the following equation was proposed:

$$
\frac{R}{h_{0}}=2.831\left(\frac{H_{1}}{h_{0}}\right)^{1.25} \cdot \sqrt{\cot \alpha} .
$$

Li \& Raichlen [14] predicted maximum run-up with nonlinear theory. They made small changes in the 
above equation and proposed the revised equation as follows:

$$
\begin{aligned}
\frac{R}{h_{0}}= & 2.831(\cot \alpha)^{0.5}\left(\frac{H_{1}}{h_{0}}\right)^{1.25} \\
& +2.293(\cot \alpha)^{1.5}\left(\frac{H_{1}}{h_{0}}\right)^{2.5} .
\end{aligned}
$$

In this study, the mentioned equation fits the obtained results of Jilani's tests, in which the placement pattern of armor units is different, such as regular and irregular types: A and B.

In order to evaluate the results of neural network model, they have been compared with the results in [6] in terms of normalized Mean Squared Error (MSE), which is defined as follows:

$$
\operatorname{MSE}=\frac{1}{N} \sum_{i=1}^{N}\left(y_{i}-\hat{y}_{i}\right)^{2},
$$

where $y_{i}$ is a predicted value; $\hat{y}_{i}$ is an observable value; and $N$ is the number of observations.

\section{Artificial neural network}

Artificial Neural Network (ANN) simulates the human nervous system, which is an attempt at the structure of the brain, such as learning ability, generalization, and decision-making. To obtain many waves near the breakwater, an ANN can be used in wave prediction, by which the analysis time for the expected failure can decrease [22].

A multilayer neural network, trained with the Back Propagation (BP) algorithm, is called MultiLayer Perceptron (MLP) network. The BP algorithm is to plan the process of the inputs to the desired outputs by minimizing the errors between the desired outputs and the calculated outputs derived from the inputs and network learning. Hyperbolic tangent functions and $\mathrm{BP}$ are often utilized in a MLP network [24].

The training of the network by BP includes three steps: the feed forward of the input training pattern, the calculation of the errors, and the setting of the weights. In this study, MLP network is used because it can learn any continuous mapping to an arbitrary accuracy [25].

Artificial Neural Network involves three layers: input layer, hidden layer, and output layer. There are one or more processing nodes that are called 'neurons'. Each neuron in each layer takes information from the front layer through connectivity. The input of neuron includes a weighted sum of the outputs of the front layer. A neural network consists of several interconnected neurons; each neuron is composed of independent units of computation per unit of input [26,
27]. Output is calculated from the following equation:

$$
y_{i}=f\left\lfloor\sum X_{i} W_{i j}+\beta\right\rfloor
$$

where $X_{i}$ is input unit, $W_{i j}$ is network weight (from input unit $X_{i}$ to hidden unit $Z_{j}$ ), and $\beta$ is bias. The above equation, $y_{i}$, is activation function [24]. One of the usual activation functions is the binary sigmoid function, which is described as:

$$
f(x)=\frac{1}{1+\exp (-x)},
$$

where $f(x)$ is activation function, and $\exp (-x)$ is exponential function. Figure 2 shows the diagram of a one-hidden-layered MLP network structure, where $y_{k}$ is output unit, and $w_{j k}$ is the network weight (from $Z_{j}$ to $\left.y_{k}\right)$.

In a feed forward network, $X_{i}$ is initially entered into the input layer, then is transferred to hidden layer. After multiplying the weights $W_{i j}$ by the values of inputs, the results are transferred to hidden layer neurons, and then these values are summed and the result is added to the bias $\beta$. Then, this amount will be transferred to the activation function. When inputs are combined to reach a certain threshold, the nerve cells are stimulated, so the signal produces an output. In this process, sample entries, synthesis and their transference occur in the output layer. A comparison of the network output with the desired value shows that Error vector is calculated, so this vector spreads from the beginning to the end of the network using different algorithms such as error BP; so that in the next cycle, the error decreases. This process, which reduces network error, is called network training.

The samples are considered in order to get enough input samples to train, validate, and test the ANN, and accordingly investigate the effect of the

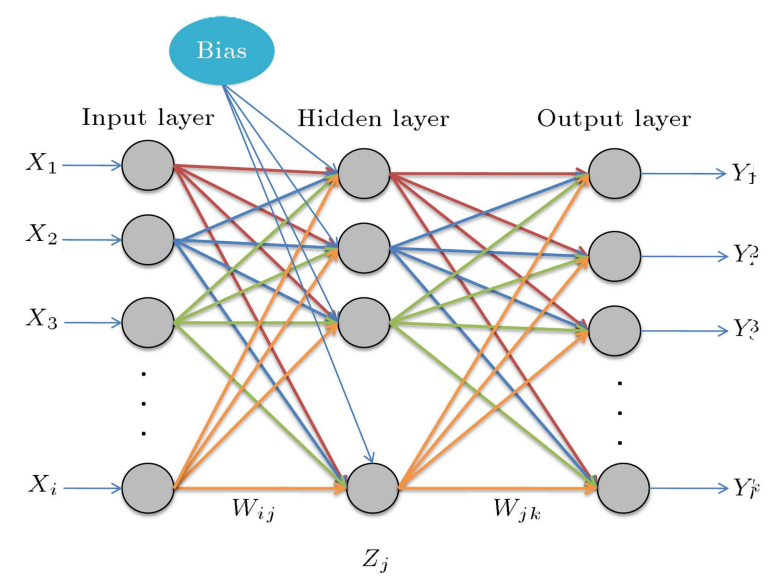

Figure 2. MLP network structure [25]. 
Table 1. The range of parameters influencing the wave run-up in the samples of Jilani [5,23].

\begin{tabular}{ccc}
\hline Variables & Range of parameters & Dimension \\
\hline Placement patterns & Regular, Irregular A \& B & {$[-]$} \\
Slope of breakwater $(\cot \alpha)$ & $1,1.5,2,2.5$ & {$[-]$} \\
wave height $\left(H_{i}\right)$ & $8,12,16,20$ & {$[\mathrm{~cm}]$} \\
wave period $(T)$ & 0.0017 & {$[\mathrm{~s}]$} \\
water depth $\left(h_{0}\right)$ & 80 & {$[\mathrm{~cm}]$} \\
\hline
\end{tabular}

placement patterns of antifer units, the front slope angle of the breakwater $(\cot \alpha)$, the incident wave height $\left(H_{i}\right)$, and incident wave period $(T)$. Table 1 determines scope of variables.

In order to study the wave run-up using Jilani's samples [5], 192 samples are used for training and calibrating the MLP network; $70 \%$ (134 samples) for training, $15 \%$ (29 samples) for validation, and $15 \%$ (29 samples) to test the trained ANN. These samples are chosen randomly for training the ANN, and the training samples are used for updating the network weights, while the validation samples are employed to stop the optimization procedure.

The present investigation zooms in on the advancement of a neural network for estimating wave run-up. One way is a basic addition, since the neural network method outcomes in instrument act for operators as a sort of black box [23].

\section{Results and discussion}

An epoch is equivalent to one cycle of the complete set of training vectors. Generally, many epochs are needed for training a back propagation neural net [24].

Figure 3 portrays the decrease of Mean Squared Error (MSE) for the training, validating, and testing samples versus training replication (Epoch). It can be seen that up to epoch 4, MSE of validation samples decreases, then it does not take any other less value in the following epochs. The training process stops in epoch 4 (MSE $=0.00096)$ in order to avoid overfitting in training samples. The number of the best epoch denotes after this epoch; changes become inconsiderable; slope of changes approximately becomes horizontal; and weights update stop.

After training the network, the number of hidden neurons should be selected. As illustrated in Table 2,

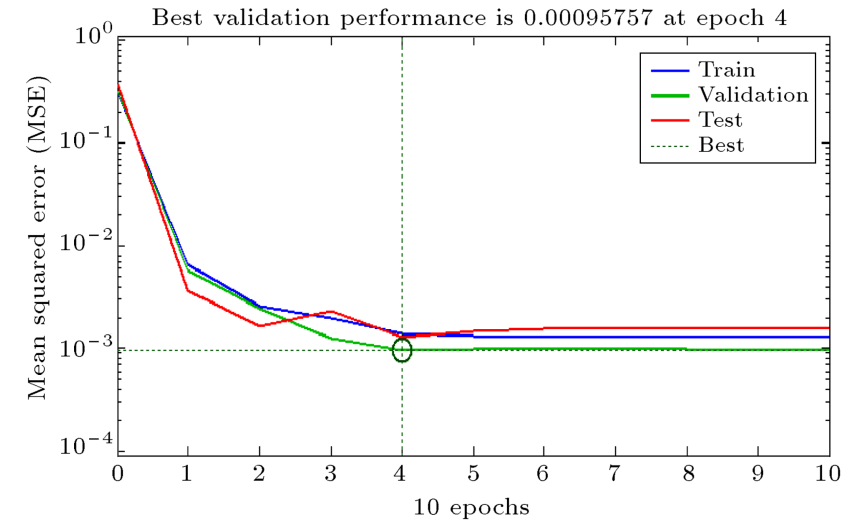

Figure 3. The decrease of MSE for the training, validating, and testing samples versus training replication.

by increasing the number of hidden neurons, MSE of the training samples decreases while MSE of validation samples reduces up to seven neurons and increases from seven neurons onwards. Thus, to avoid over-fitting, the number of seven hidden neurons is chosen in the hidden layer of the neural network.

The testing samples are used to investigate the performance of ANN to be appropriate. In other words, the main reason for utilizing the testing samples is to evaluate the model validity, in which after some point in the training method, over-fitting starts on the training samples.

The testing samples have no effect on training; so, they provide an independent measure of network performance during and after the training. The validation samples are used to measure network generalization and to halt when generalization stops improving.Figure 4 depicts the generalization of the trained ANN in the training, validating, and testing samples. It also shows the best linear fit for the samples. Moreover, the obtained results illustrate that the

Table 2. MSE of training, testing, and validating samples for the various hidden neurons.

\begin{tabular}{cccccc}
\hline Hidden neurons & $\mathbf{5}$ & $\mathbf{6}$ & $\mathbf{7}$ & $\mathbf{8}$ & $\mathbf{9}$ \\
\hline Training & 0.0029 & 0.0022 & 0.0022 & 0.0015 & 0.0012 \\
Validation & 0.0019 & 0.0017 & 0.0016 & 0.0045 & 0.0046 \\
Testing & 0.0032 & 0.0016 & 0.0023 & 0.0019 & 0.0049 \\
Epochs & 4 & 6 & 4 & 6 & 10 \\
\hline
\end{tabular}



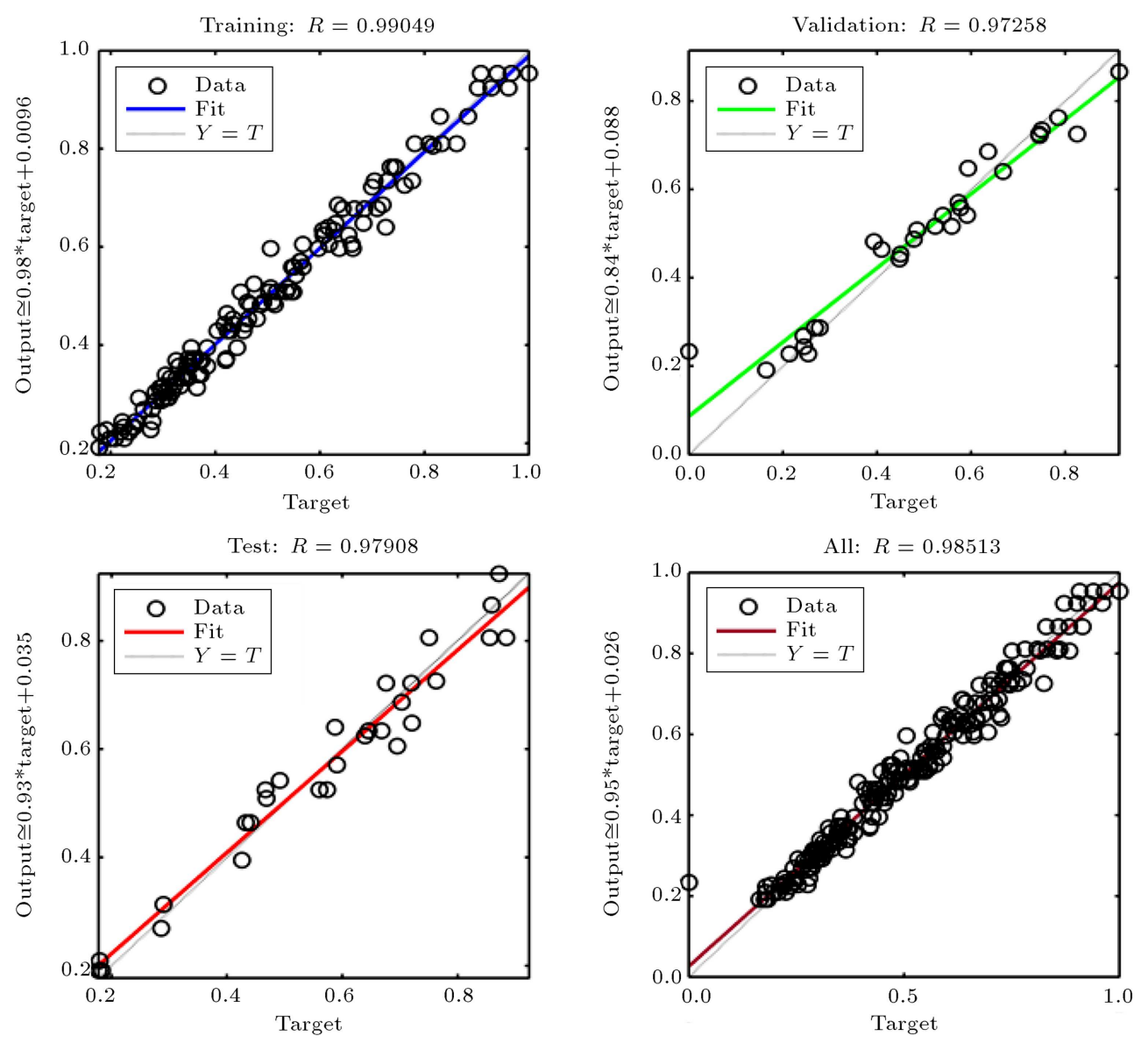

Figure 4. The correlation between the predicted values of ANN and experimental values for validating, training, and test samples.

predicted values of ANN for run-up (output) have an acceptable correlation $(\mathrm{R})$ with the measured samples of Jilani's experiments (Target) for all of validating, training, and testing samples. As illustrated in Figure 5 , the verification of the presented model (ANN), using Jilanis's measured samples for wave run-ups on a breakwater, is covered by different types of antifer. In other words, acceptable agreement can be observed between predicted values and measured samples (Figure 5(a), (b) and (c)). Also, the reliability of the presented model is obtained, especially for rubblemound breakwater protected with antifer blocks.

The main aim of a consideration into wave runup is to inspect the effect of the placement pattern of antifer units on the wave run-up. In order to accede to this goal, training of ANN was carried out with results of Jilani's experiments, then the correlation of obtained results of ANN model compared the correlation of obtained results of ANN model with the experimental results of other studies. Figure 6 shows the best fitting line for the data for models of (a) ANN, (b) Synolakis [10], (c) Li\&Riachlen [12], and (d) Hughes [14]. The obtained correlation of these studies and its comparison with the ANN model, listed in Table 3, represent that the correlation of obtained results of the ANN model is higher than that of other studies. So, the ANN model is acceptable to calculate wave run-up on the breakwater covered by antifer units with different placement patterns.

As illustrated in Tables 4 and 5, the Regression equations and MSE for the results obtained by ANN are compared with other models in the literature. With respect to the obtained results, it can be concluded that the regular placement should be preferred to other placement patterns due to its less MSE obtained by ANN. Moreover, from the evaluation of ANN modeling, it can be concluded that the regular placement methods behave more stable than the irregular placement.

Table 3. Comparing the obtained correlation between ANN modeling and models of Synolakis [10], Li \& Riachlen [12], and Hughes [14].

\begin{tabular}{cc}
\hline Researches & Calculated correlation $(\boldsymbol{R})$ \\
\hline Synolokis [10] & 0.84318 \\
Li\& Riachlen [12] & 0.83513 \\
Hughes [14] & 0.87366 \\
ANN & 0.98547 \\
\hline
\end{tabular}




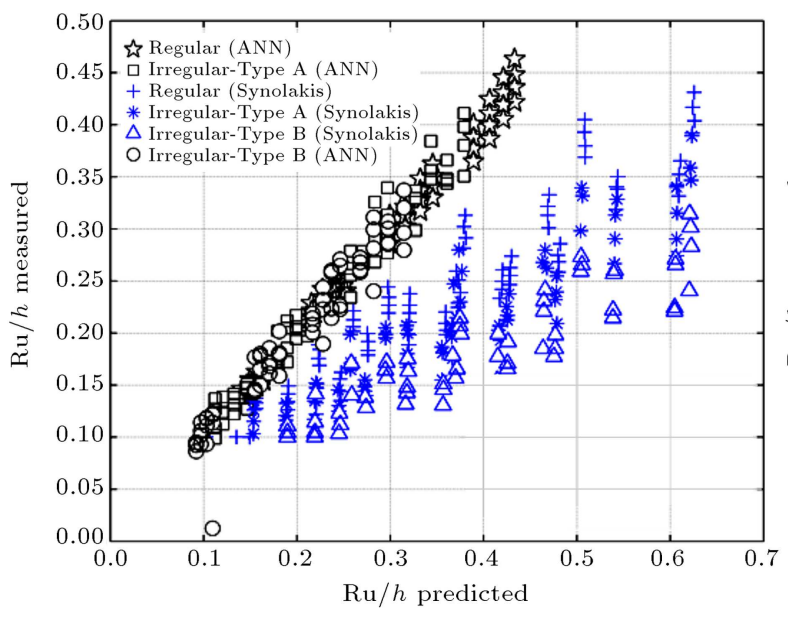

(a)

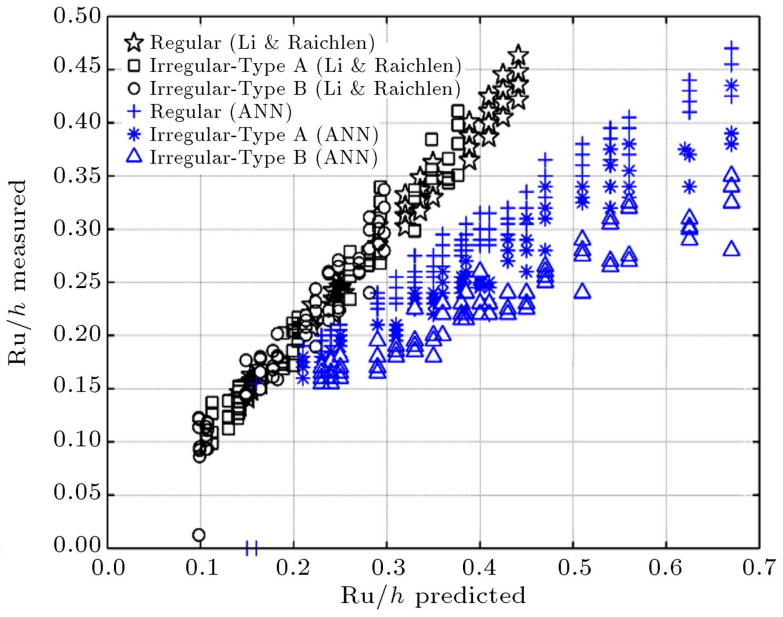

(b)

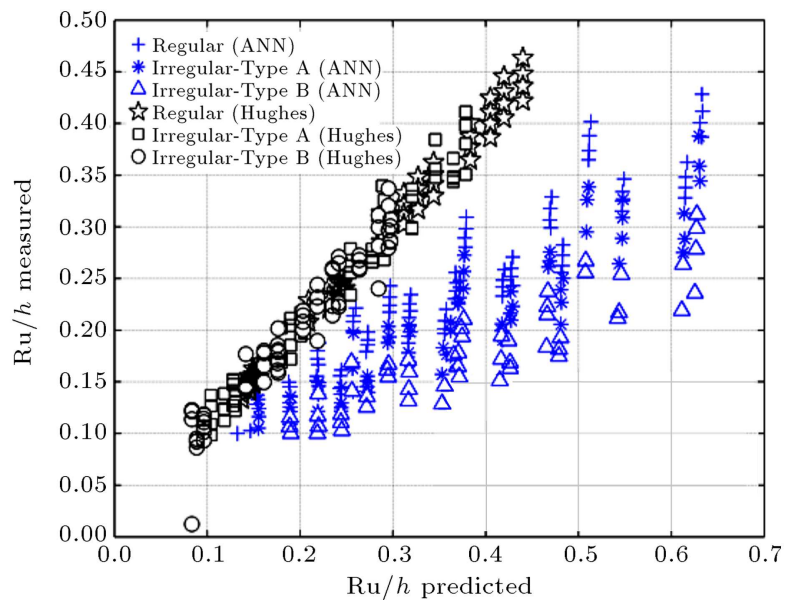

(c)

Figure 5. The measured samples versus the predicted wave run-up (Ru) in the obtained results of ANN, and experiments of (a) Synolakis [10], (b) Li \& Riachlen [12], and (c) Hughes [14] over the breakwater covered by antifer units with difference placement patterns.

Table 4. The regression equations and calculated MSE in the experiments of Synolokis [10], Li \& Riachlen [12,23], and Hughes [14,23] over the breakwater covered by antifer units with difference placement pattern.

\begin{tabular}{ccccccc}
\hline Types of pattern & Synolokis [10] & MSE & Li \& Riachlen [12,23] & MSE & Hughes [14,23] & MSE \\
\hline Regular & $Y=0.56 X+0.35$ & 0.0193 & $Y=0.64 X-0.036$ & 0.0202 & $Y=0.54 X+0.044$ & 0.0139 \\
Irregular Type A & $Y=0.49 X+0.03$ & 0.0302 & $Y=0.52 X-0.054$ & 0.0316 & $Y=0.47 X+0.033$ & 0.0223 \\
Irregular Type B & $Y=0.39 X+0.03$ & 0.0522 & $Y=0.38 X-0.072$ & 0.0506 & $Y=0.37 X+0.035$ & 0.0398 \\
\hline
\end{tabular}

Table 5. The regression equations and the calculated MSE of the results of ANN, compared with the obtained results of Table 4.

\begin{tabular}{ccc}
\hline Types of pattern & ANN & MSE (ANN) \\
\hline Regular & $Y=0.99 X+0.005$ & 0.0001 \\
Irregular Type A & $Y=0.97 X+0.011$ & 0.0003 \\
Irregular Type B & $Y=0.97 X+0.010$ & 0.0004 \\
\hline
\end{tabular}

\section{Conclusions}

As illustrated in Tables 4 and 5, the Regression equations and MSE for the results obtained by ANN are compared with other models in the literature. With respect to the obtained results, it can be concluded that the regular placement should be preferred to other placement pattern due to its less MSE obtained by ANN. Moreover, from the evaluation of ANN modeling, it can be concluded that the regular placement 


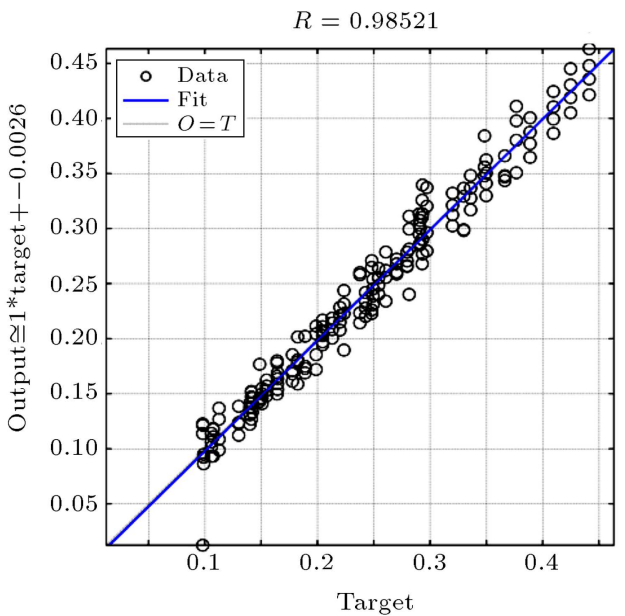

(a)

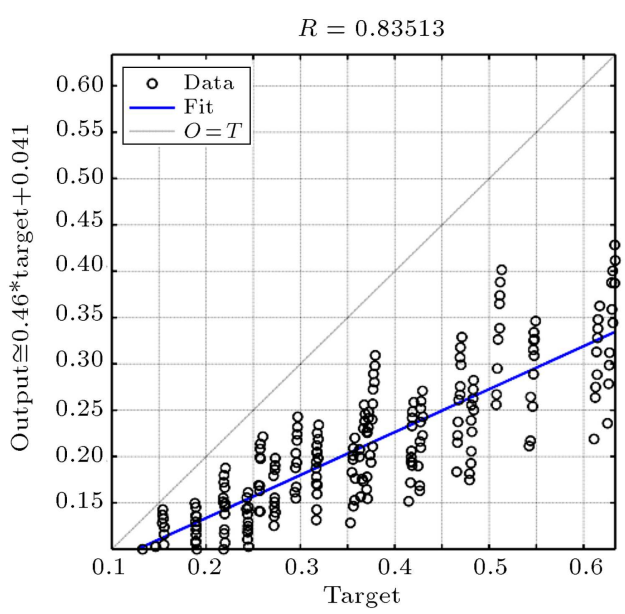

(c)

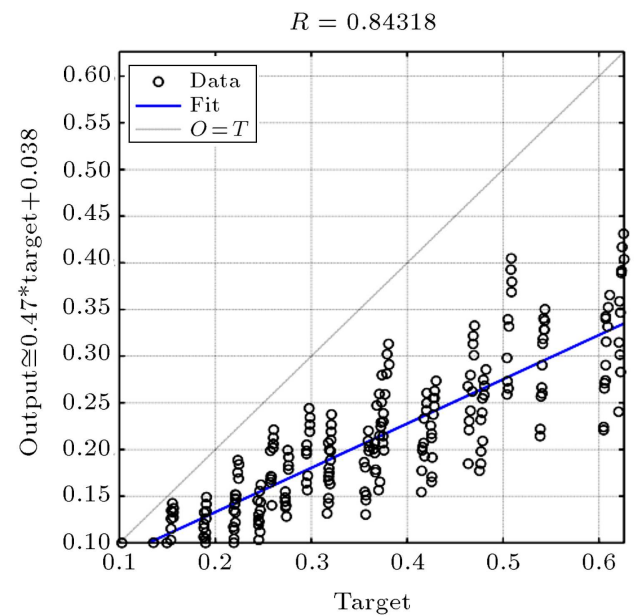

(b)

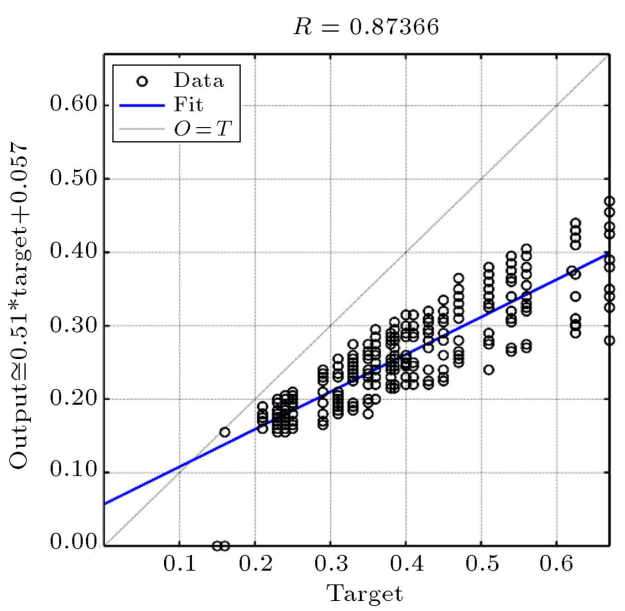

(d)

Figure 6. The best linear fit for the data for models of (a) ANN, (b) Synolakis [10], (c) Li \& Riachlen [12], and (d) Hughes [14].

methods behave more stable than the irregular placement.

\section{Nomenclature}

$\alpha \quad$ Front slope angle of the breakwater (deg)

$\beta \quad$ Bias

$\gamma_{\omega} \quad$ Water density $\left(\mathrm{M}^{\mathrm{T}^{-2} \mathrm{~L}^{-2}}\right)$

$f \quad$ Function defined to related inputs and their weight in the neural network

(Eq. (9))

$h_{0} \quad$ Still water depth (L)

$H_{i} \quad$ Incident wave height

$K_{p} \quad$ Empirical coefficient indicating the placement of antifer units (-) in run-up estimation (-)

$L_{i} \quad$ Incoming wave length (L)
$M, N \quad$ Empirical coefficients to estimate incoming wave moment flux (Eqs. (4) and (5))

$M_{F} \quad$ Moment flux of the incident wave (Eq. (3))

$n$

Number of observation for calculating MSE

$T \quad$ Incoming wave period $(\mathrm{T})$

$R \quad$ Value of correlation (-)

$\mathrm{Ru} \quad$ Wave run-up on the breakwater (L)

$w_{i j} \quad$ Weight in the neural network

$x_{i} \quad$ Input unit in the neural network

$y_{i} \quad$ Predictive value for calculating MSE

$\hat{y}_{i} \quad$ Observable value for calculating MSE

$y_{k} \quad$ Activation function in the neural network

$z_{j} \quad$ Hidden unit in the neural network 


\section{References}

1. Yagci, O., Kapdasli, S. "Alternative placement technique for antifer blocks used on breakwaters", Ocean Engineering, 30(11), pp. 1433-1451 (2003).

2. Günbak, A.R. "Antifer cubes on rubble mound breakwaters", Proceedings of the COPEDEC, Cape Town, South Africa (1999).

3. Shankar, N.J., Jayaratne, M.P.R. "Wave run-up and overtopping on smooth and rough slopes of coastal structures", Ocean Engineering, 30(2), pp. 221-238 (2003).

4. Hudson, R.Y., Herrmann, F.A. and Sager, R.A., Coastal Hydraulic Models, No. SR-5 (1979).

5. Najafi-Jilani, A. and Monshizadeh, M. "Laboratory investigations on wave run-up and transmission aver breakwaters coverd by antiferunits", Scientia Iranica, 17(6), pp. 457-470 (2010).

6. Bakhtyar, R., Yeganeh-Bakhtiary, A. and Ghaheri, A. "Application of neuro-fuzzy approach in prediction of runup in swash zone", Applied Ocean Research, 30(1), pp. $17-27$ (2008).

7. Frens, A.B. "The impact of placement method on antifer-block stability", Diss. M. Sc. Thesis, Delft University of Technology (2007).

8. Battjes, J.A. "Run-up distributions of waves breaking on slopes", Journal of the Waterways, Harbors and Coastal Engineering Division, 97(1), pp. 91-114 (1971).

9. Synolakis, C.E. "The runup of long waves" (2007).

10. Synolakis, C.E. "The runup of solitary waves", $J$. Fluid Mech185, pp. 523-545 (1987).

11. Van der Meer, J.W. and Stam, C.J.M. "Wave runup on smooth and rock slopes of coastal structures", Journal of Waterway, Port, Coastal, and Ocean Engineering, 118(5), pp. 534-550 (1992).

12. Ying, Li. and Raichlen, F. "Solitary wave runup on plane slopes", Journal of Waterway, Port, Coastal, and Ocean Engineering, 127(1), pp. 33-44 (2001).

13. Van de Walle, B.J., Wave Run-Up on Rubble Mound Breakwaters, Diss. Ghent University (2003).

14. Hughes, S.A. "Estimation of wave run-up on smooth, impermeable slopes using the wave momentum flux parameter", Coastal Engineering, 51(11), pp. 1085-1104 (2004).

15. Schüttrumpf, H., Van der Meer, J., Kortenhaus, A., Bruce, T. and Franco, L., Wave Run-Up and Wave Overtopping at Armored Rubble Slopes and Mounds. Handbook of Coastal and Ocean Engineering, Word Scientific Publishing Co. Pte. Ltd., Singapore, pp. 383-411 (2010).

16. Dentale, F., Donnarumma, G. and Carratelli, E.P. "Wave run up and reflection on tridimensional virtual breakwater", Journal Hydrogeology \& Hydrologic Engineering, 1(1), pp. 102-110 (2012).

17. Dentale, F., Donnarumma, G. and Pugliese Carratelli, E. "Rubble mound breakwater: run-up, reflection and overtopping by numerical 3D simulation", In Proceedings of a Conference on Coasts, Marine Structures and Breakwaters, pp. 1-10 (2013).

18. Erdik, T. "Mamdani approach for $2 \%$ wave run-up on breakwaters", Journal of Intelligent and Fuzzy Systems, 26(1), pp. 1-9 (2014).

19. Najafi-Jilani, A., Zakiri Niri, M. and Naderi, N. "Simulating three dimensional wave run-up over breakwaters covered by antifer units", International Journal of Naval Architecture and Ocean Engineering, 6(2), pp. 297-306 (2014).

20. Altomare, C., Crespo, A.J., Rogers, B.D., Domínguez, J.M., Gironella, X. and Gómez-Gesteira, M. "Numerical modelling of armour block sea breakwater with smoothed particle hydrodynamics", Computers \& Structures, 130, pp. 34-45 (2014).

21. Crespo, A., Altomare, C., Rogers, B. D., Dominguez, J. and Gironella Cobos, X. "Numerical modelling of coastal defences using the smoothed particle hydrodynamic method". In Book of Proceedings of the 4 th International Conference on the Application of Physical Modelling to Port and Coastal ProtectionCoastlab12, pp. 728-737 (2013).

22. Kim, D.H., Kim, Y.J. and Hur, D.S. "Artificial neural network based breakwater damage estimation considering tidal level variation", Ocean Engineering, 87, pp. 185-190 (2014).

23. Rabiei, A., Najafi-Jilani, A. and Zakeri-Niri, M. "Wave run-up prediction on antifer armor using neural network method", Coastal Engineering Proceedings, $\mathbf{1}(34)$, p. 52 (2014).

24. Jabbari, E. and Talebi, O. "Using artificial neural networks for estimation of scour at the head of vertical wall breakwater", Journal of Coastal Research, 64, p. 521 (2011).

25. Fausett, L. "Fundamentals of neural networks", Architectures, Algorithms, and Applications, Pearson Education India (2006).

26. Huang, Y. "Advances in artificial neural networksmethodological development and application", Algorithms, 2(3), pp. 973-1007 (2009).

27. Van der Meer, J.W., Van Gent, M.R., Pozueta, B., Verhaeghe, H., Steendam, G.J. and Medina, J.R. "Applications of a neural network to predict wave overtopping at coastal structures", ICE, Coastlines, Structures and Breakwaters, London, pp. 259-268 (2005).

\section{Biographies}

Arezoo Rabiei obtained an MS degree in Civil-Water Engineering from Islamic Azad University, Islamshahr Branch, Iran, in 2014. She has written 3 conference 
papers, and has presented one of papers on ICCE2014 conference. Her main research interests include coastal engineering and hydraulic structures.

Ataollah Najafi Jilani earned his BS degree in Civil Engineering in 1995 from Amir kabir University of Technology, Tehran, Iran, his MS degree in Hydraulic Structures Engineering in 1997 from Tehran University, Iran, and his PhD degree in Civil-Hydraulic Engineering in 2007 from Sharif University of Technology, Tehran, Iran. He is currently an Assistant Professor of Civil Engineering in the Islamic Azad University, Islamshahr Branch, Iran. His major awards are the 22nd Khawrizmi International Award (2009) for third rank in applicable researchers in Iran entitled "Landslide GeneratedWaves in Dam Reservoirs". He was the first co-author of this project. He was ranked the first among graduated $\mathrm{PhD}$ students in Civil Engineering Department in Sharif University of Technology, and so earned the Tavakkoli Prize of Civil Engineering Faculty (2009). He achieved to be the first rank among graduated MSc students and earned the graduation ceremony award in University of Tehran (1997). Dr. Najafi Jilani has written 10 journal papers and more than 26 national and international conference papers. His main research interests include numerical and experimental investigations on hydraulic engineering, coastal hydrodynamics, marine structures, and coastal sedimentation.

Mahmoud Zakeri Niri earned his BSc degree in Civil Engineering in 2002 from Zanjan University, Zanjan, Iran, his MSc degree in Civil-Water Engineering in 2004 from Amir kabir University of Technology, Tehran, Iran, and his $\mathrm{PhD}$ degree in the same field, in 2011, from Islamic Azad University (IAU), Science and Research Branch, Tehran, Iran.

$\mathrm{He}$ is currently an Assistant Professor of Civil Engineering in the Islamic Azad University, Islamshahr branch, Iran.

His major awards were the first rank in entrance exam PhD students in Civil-Water Engineering Department in Islamic Azad University, Science and search Branch, Tehran, Iran. He was also the third rank in graduated MSc. He earned the graduation ceremony award in Amirkabir University of Technology (2004), Tehran, Iran.

Dr. Zakeri Niri has written 4 journal papers and more than 15 national and international conference papers. His main research interests include kinematic and dffusion waves, water resources management, hydrology, surface water, ground water, numerical and experimental investigations on rainfall-runoff modeling. 